\title{
"How can I help you hear?" The transforming power of six little words
}

\section{Sarah Chapman \\ In the latest of a monthly series in which patients and carers set the learning outcomes for readers, Sarah Chapman offers practical advice when talking to people with hearing loss. For more information about the series, contact Rosamund Snow, patient editor, rsnow@bmj.com.}

I'm waiting to be called for a smear and I have a couple of concerns to discuss. I'm on high alert. Not for me a browse of last year's magazines; I need to be sure that I know when I'm called, and that means keeping my eyes peeled for the nurse. Having made it to the consulting room, the next obstacle is the "confidential tone"- the enemy of every patient with hearing loss. We stumble our way through a series of questions, half heard, on intimate matters (plenty of scope here for misunderstanding and embarrassment), and I ready myself for the next bit of the ordeal.

Now an internal examination is not likely to gladden the heart, but because I rely on seeing lip movements to aid my hearing, being flat on my back threatens more than just my dignity. I'm grateful that the nurse offers me privacy to get undressed but miss what she's saying from the other side of the curtain. I'm prepared for the business of trying to keep my head raised off the trolley, to increase my chances of keeping my eyes on her face, but of course I can't sustain it and sometimes she talks with her back turned, her head down, or from behind the curtain. Worse is to come. I'm still on the trolley as she gives me a short lesson on my physiology using the curtain and her hand as explanatory props, her face half hidden behind. I can't fault her ingenuity but leave no wiser than when I arrived.

A desire to be polite and not risk irritating the person in whose hands I quite literally found myself meant that on this, as on other occasions, I acted as if I had heard and understood, thanked her, and left her to get on with the next patient. A letter would be sent, I told myself, and I got a sense there was nothing to worry about, so I'd just wait.

If you don't have hearing loss, it must be hard to see why I can't just say that I do, problem solved. It's not quite that simple, not least because hearing loss threatens our communication all the time that we're talking. It's hard to keep interrupting a consultation to say, again, that I didn't hear. Everyone misses bits of conversation sometimes, and as someone with hearing loss I accept that I will miss more than most. I have to try to get the balance right between interrupting to clarify something half heard and letting some things go, hoping the words I lose aren't crucial. Then there are the times that really trip me up-when I'm unaware that I've misheard until an odd look or long pause from the person talking to me gives me a clue that I've got it wrong. Being a patient is potentially stressful, and difficulties with communication add to this. It's very tempting, when I'm struggling to hear, to end the conversation quickly rather than stick at it.

When I go into your consulting room, as your patient or perhaps accompanying someone else, I'm always a person with hearing loss, whatever else might ail me. I might rail against you seeing me primarily as a middle aged white woman, or the other things that might colour your impression when I walk through the door, but I need you to remember this thing and work with me to accommodate it, all the time, every time.

Without this, we're not going to be able to have a helpful dialogue; little chance of you being able to share your expertise and me my values and concerns, little chance of us making decisions together. You'll be left having only partly reached me and I'll walk away wondering quite how much I missed, perhaps unsure about what will happen next and why.

I've no idea if patient records are marked to flag up when a person has hearing loss, but I'd like them to be. I'd like my healthcare provider to be ready for that, but I must be ready to tell you, to be sure you know that from the start.

I arrive in a café for a first meeting with someone with shared professional interests, whom I know only through Twitter. She knows I' $m$ hard of hearing and when I immediately eject her from her seat in front of a window, offering an awkward explanation that I need to sit where I can best see her face, she asks me "how can I help you hear?" There might as well be fireworks and a full orchestral accompaniment, so great is my surprise at being asked this for the first time ever in three decades as a hearing aid wearer, and so powerful is its effect.

Competing interests: I have read and understood BMJ policy on declaration of interests and have no interests to declare.

Provenance and peer review: Commissioned; not externally peer reviewed.

Further resources: Sarah has registered the \#howcanlhelpyouhear hashtag with Symplur's Healthcare Hashtags Project and she hopes that this will act as a reminder to healthcare professionals on Twitter and encourage discussion. 


\section{Key messages:}

1. Please don't ignore my hearing loss. Acknowledge it and ask "how can I help you hear?" This empowers us both. It's a respectful, empathetic, and practical opening question, inviting specific instructions that you can follow, knowing that you are doing the right things to enable a helpful dialogue. I'm immediately made to feel that you're on my side, that we're partners in this business of managing my health, and I'm able to tell you what I need you to do. For me, that's making sure you're not sitting with a window behind you, and that you speak clearly and only when I can see your face. It's not much to ask and it won't take any longer; in fact it will save time. Others may have different needs and they'll be able to tell you what they are.

2. It's easy to start well but soon forget to do the things that help me hear, so keep checking that you're still doing them.

3. Consider supporting your verbal communication with visual information, such as diagrams. Unfamiliar terms can be hard to hear correctly, so I might like them written down. 